\title{
Regional expiratory time constants in severe respiratory failure estimated by electrical impedance tomography: a feasibility study
}

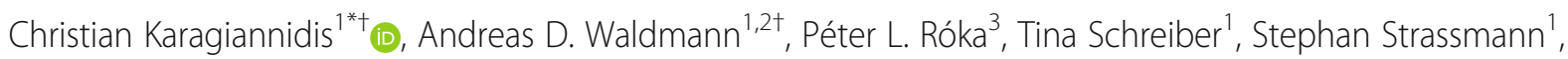
Wolfram Windisch ${ }^{1}$ and Stephan H. Böhm ${ }^{4}$

\begin{abstract}
Background: Electrical impedance tomography (EIT) has been used to guide mechanical ventilation in ICU patients with lung collapse. Its use in patients with obstructive pulmonary diseases has been rare since obstructions could not be monitored on a regional level at the bedside. The current study therefore determines breath-by-breath regional expiratory time constants in intubated patients with chronic obstructive pulmonary disease (COPD) and acute respiratory distress syndrome (ARDS).

Methods: Expiratory time constants calculated from the global impedance EIT signal were compared to the pneumatic volume signals measured with an electronic pneumotachograph. EIT-derived expiratory time constants were additionally determined on a regional and pixelwise level. However, regional EIT signals on a single pixel level could in principle not be compared with similar pneumatic changes since these measurements cannot be obtained in patients. For this study, EIT measurements were conducted in 14 intubated patients (mean Simplified Acute Physiology Score II (SAPS II) $35 \pm$ 10, mean time on invasive mechanical ventilation $36 \pm 26$ days) under four different positive end-expiratory pressure (PEEP) levels ranging from 10 to $17 \mathrm{cmH}_{2} \mathrm{O}$. Only patients with moderate-severe ARDS or COPD exacerbation were included into the study, preferentally within the first days following intubation.
\end{abstract}

Results: Spearman's correlation coefficient for comparison between EIT-derived time constants and those from flow/ volume curves was between 0.78 for tau $(\tau)$ calculated from the global impedance signal up to 0.83 for the mean of all pixelwise calculated regional impedance changes over the entire PEEP range. Furthermore, Bland-Altman analysis revealed a corresponding bias of 0.02 and $0.14 \mathrm{~s}$ within the limits of agreement ranging from -0.50 to $0.65 \mathrm{~s}$ for the aforementioned calculation methods. In addition, exemplarily in patients with moderate-severe ARDS or COPD exacerbation, different PEEP levels were shown to have an influence on the distribution pattern of regional time constants.

Conclusions: EIT-based determination of breath-by-breath regional expiratory time constants is technically feasible, reliable and valid in invasively ventilated patients with severe respiratory failure and provides a promising tool to individually adjust mechanical ventilation in response to the patterns of regional airflow obstruction.

Trial registration: German Trial Register DRKS 00011650, registered 01/31/17.

Keywords: Severe COPD, Exacerbation, ARDS, Expiratory time constant, Flow limitation, Electrical impedance tomography

\footnotetext{
* Correspondence: Christian.Karagiannidis@uni-wh.de

${ }^{\dagger}$ Christian Karagiannidis and Andreas D. Waldmann contributed equally to this work.

${ }^{1}$ Department of Pneumology and Critical Care Medicine, Cologne-Merheim

Hospital, Kliniken der Stadt Köln gGmbH, Witten/Herdecke University

Hospital, Ostmerheimer Strasse 200, D-51109 Cologne, Germany

Full list of author information is available at the end of the article
}

(c) The Author(s). 2018 Open Access This article is distributed under the terms of the Creative Commons Attribution 4.0 International License (http://creativecommons.org/licenses/by/4.0/), which permits unrestricted use, distribution, and reproduction in any medium, provided you give appropriate credit to the original author(s) and the source, provide a link to the Creative Commons license, and indicate if changes were made. The Creative Commons Public Domain Dedication waiver (http://creativecommons.org/publicdomain/zero/1.0/) applies to the data made available in this article, unless otherwise stated. 


\section{Background}

Ventilatory support in patients with severe respiratory failure is steadily increasing in modern intensive care medicine. Although substantial progress has been made, mortality in ICU patients still remains high [1, 2]. Individualizing treatment to specific patient needs is suggested to improve the outcome particularly in ICU patients on ventilatory support [3]. One important limitation, however, towards individualized ventilatory support is the lack of technology to monitor regional lung function continuously at the bedside. While lung function has been monitored by the analysis of flow and volume curve for decades, this reflects global lung function only $[4,5]$. Accordingly, these global pneumatic signals cannot distinguish differences in regional pathophysiology. In this regard, ventilator settings may have distinct or even opposite effects on different lung regions due to oscillating air/Pendelluft $[6,7]$, atelectasis or overdistension, which typically remains undetected in daily clinical practice.

Modern diagnostic techniques such as transpulmonary pressure measurement [8] or electrical impedance tomography (EIT) [9-15] when used to guide mechanical ventilation have been shown to improve gas exchange in patients with ARDS [16-20]. In particular, EIT is a unique technique to continuously determine regional differences in atelectasis and overdistension [21-27]. However, until now airflow limitation, which is a hallmark of obstructive pulmonary diseases such as asthma, chronic obstructive pulmonary disease (COPD) or bronchiolitis has never been monitored breathwise on a regional level. The estimation of regional expiratory time constants by
EIT has the potential to provide a new dimension for bedside monitoring of patients with obstructive lung diseases or even for small airway alterations in ARDS.

Although the expiratory time constants measured at the tube at airway opening summarizes time constants from different regions of the lung, it provides clinically useful information on the mechanical properties of the entire respiratory system [28, 29]. Different approaches to calculating the global expiratory time constant have been suggested in the past. Marini et al. [30] proposed a method dividing the total expiratory volume by the peak expiratory flow. Brunner et al. [31] modified this approach for cases with incomplete exhalation and could precisely determine the expiratory time constants for passive exhalation by adding a correction factor for incomplete exhalation. Although regional compliance $(C)$ and resistance $(R)$ can intra-individually vary considerably between different lung regions, the aforementioned approaches are capable of measuring a single compartment model only. To overcome this limitation and to estimate the heterogeneity of passive lung deflation, Henderson et al. [32] divided the global flow-volume curve into a sequence of five consecutive volume segments and calculated the expiratory time constant for each segment separately. All these techniques reflect the global expiratory time constants to which all lung areas contribute. In regard to regional lung function measurement, Vogt et al. [33] assessed the spatial and temporal heterogeneity of ventilation by EIT during pulmonary function testing in differentially aged subjects without lung disease and in patients with COPD [34]. Their results indicate EIT to be capable

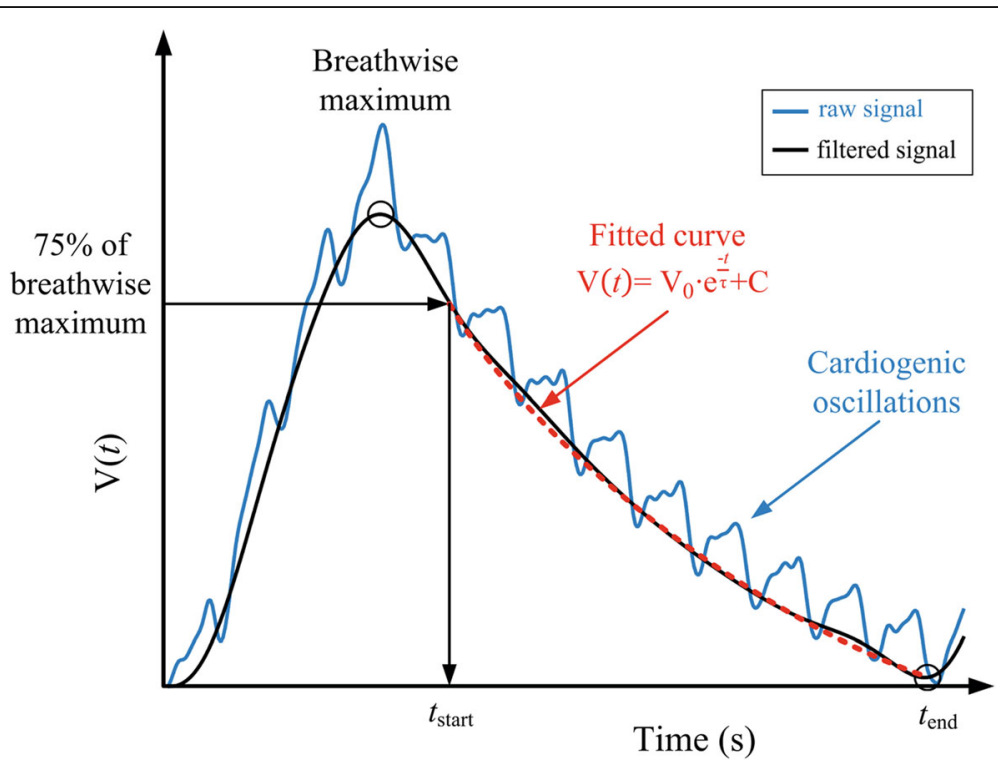

Fig. 1 Algorithm for calculating regional time constant $\tau$ reg. Of note, curve fitting starts at the time when $75 \%$ of peak signal is reached (see "Methods"). $V(t)$ : volume at time point $t, V_{0}$ volume at start of expiration, $t$ the time from the start at end-inspiration to the end of expiration, $\tau$ the expiratory time constant and $C$ the end expiratory volume 
of providing information on the spatial and temporal distribution of the emptying characteristics during a single forced exhalation. Nevertheless, the method is thus not suited for the continuous monitoring of mechanically ventilated patients.

To date, regional online airflow obstruction measurements in patients with the most severe lung failure have yet to be determined $[35,36]$. Therefore, the aim of the present study was to develop, evaluate and validate an EIT-based method to measure regional expiratory time constants on a breath by breath basis and pixelwise level. Fourteen intubated and invasively ventilated patients with severe respiratory failure resulting from moderate to severe ARDS, COPD exacerbation or lung transplant rejection were studied, and time constants were analyzed offline afterwards. Although regional changes in ventilation are the primary aim of the method, the global pneumatic vs. EIT-derived signals had to be validated, since pneumatic changes on a comparable pixel level could not be obtained at all using current technology.

\section{Methods \\ Patients and ethics}

The study was approved by the Ethics Committee of the Witten/Herdecke University and registered at the German Clinical Trial Register and the World Health Organization (WHO) trial register (DRKS00011650/ U1111-1192-0396). Patients with COPD, leading to exacerbation with invasive mechanical ventilation and those with pneumonia and/or moderate to severe ARDS ventilated at different PEEP levels were enrolled in this study. Diagnosis of COPD was made by two independent pulmonologists in accordance to the medical history, flow characteristics of the mechanical ventilation, $x$-ray of the chest and known pre-diagnosis from pulmonologists. During the study protocol PEEP was titrated by decrements from $16 / 17$ to $14 / 15$ to $12 / 13$ and

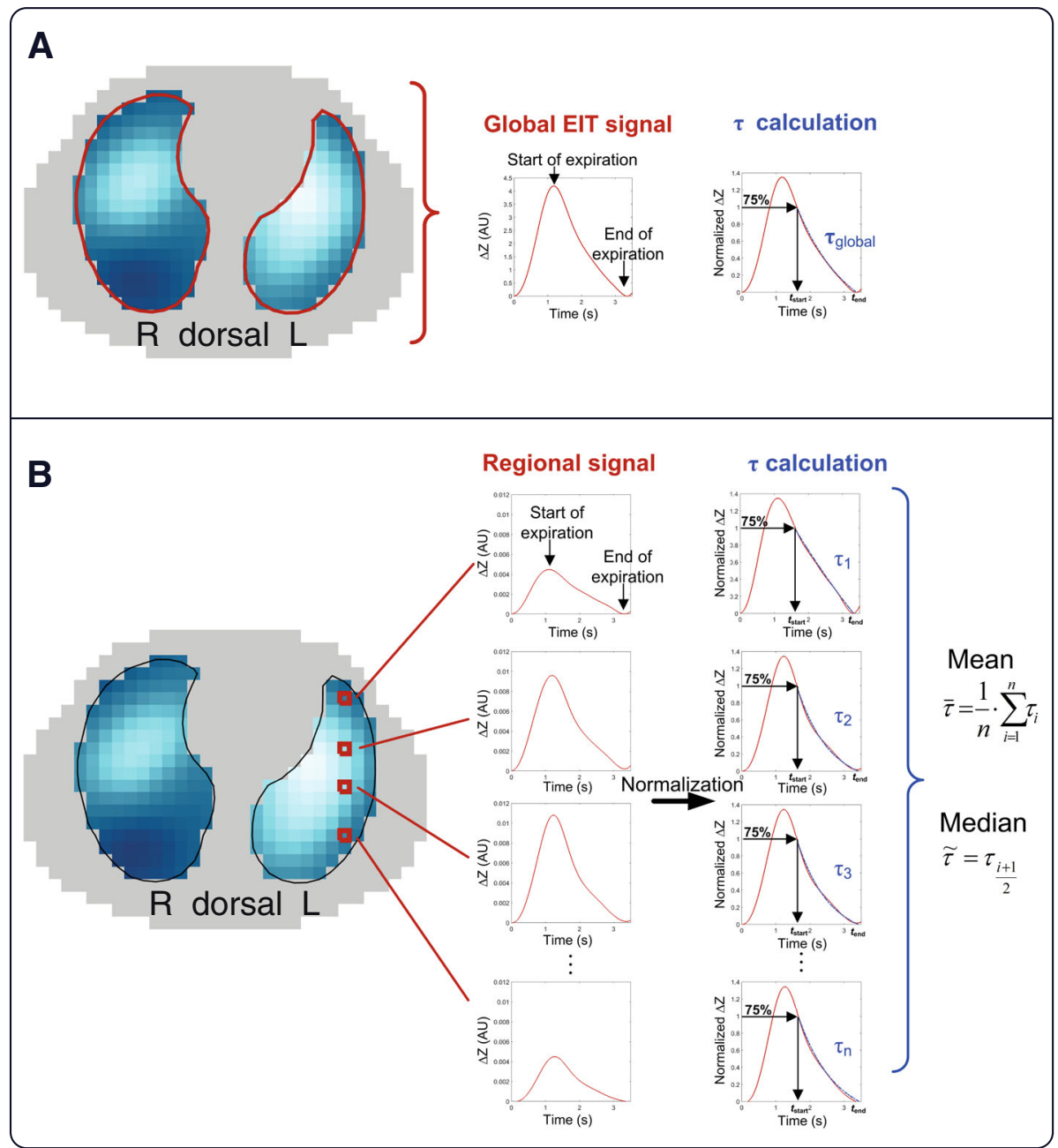

Fig. 2 Tau calculation from global (a) vs. mean or median (b) of regional tau. $\Delta Z$, impedance change. EIT, electrical impedance tomography 
$10 / 11 \mathrm{cmH}_{2} \mathrm{O}$ applying a tidal volume of $6 \mathrm{ml} / \mathrm{kg}$ predicted body weight (PBW). Every step lasted $30 \mathrm{~min}$. Patients were deeply sedated (Richmond Agitation Sedation Scale (RASS) score -4) without any spontaneous breathing effort. Pneumatic volume measurements and the corresponding EIT signal were obtained at the end of each 30-min period for post-hoc breath by breath analysis. The study was conducted in the early phase of the disease as soon as written informed consent could be obtained from the legal representative.

\section{Pneumatic measurements by electronic pneumotachograph}

Acting as reference, the global flow signal was measured with a sampling rate of $1 \mathrm{kHz}$ at the distal end of the tracheal tube using the hot-wire anemometry V-Meter (EKU, Leiningen, Germany) and integrated to obtain volumes.

\section{EIT measurements}

EIT data were measured using the Swisstom $\mathrm{BB}^{2}$ (Swisstom AG, Landquart, Switzerland). Each patient's thorax circumference was measured, and the textile electrode belt of appropriate size fastened along the 6th intercostal space [37]. Fifty cross-sectional impedance images were recorded every second for a period of 10 min under stable conditions. In addition, lung and thorax contours derived from patient-specific computer tomography (CT) scans, which were performed routinely during the course of the disease, were projected into the EIT images (Additional file 1: Figure S2). CT images were analyzed in the inspiration phase. Accordingly, only signals from the CT-defined lung regions were analyzed (Figs. 1 and 2) [38]. EIT images were low-pass filtered to suppress cardiac-related impedance changes. The cutoff frequency for the low-pass filter was adjusted for each patient individually according to the patient's heart rate. Time constants were calculated by exponential fitting for every single pixel. If the single

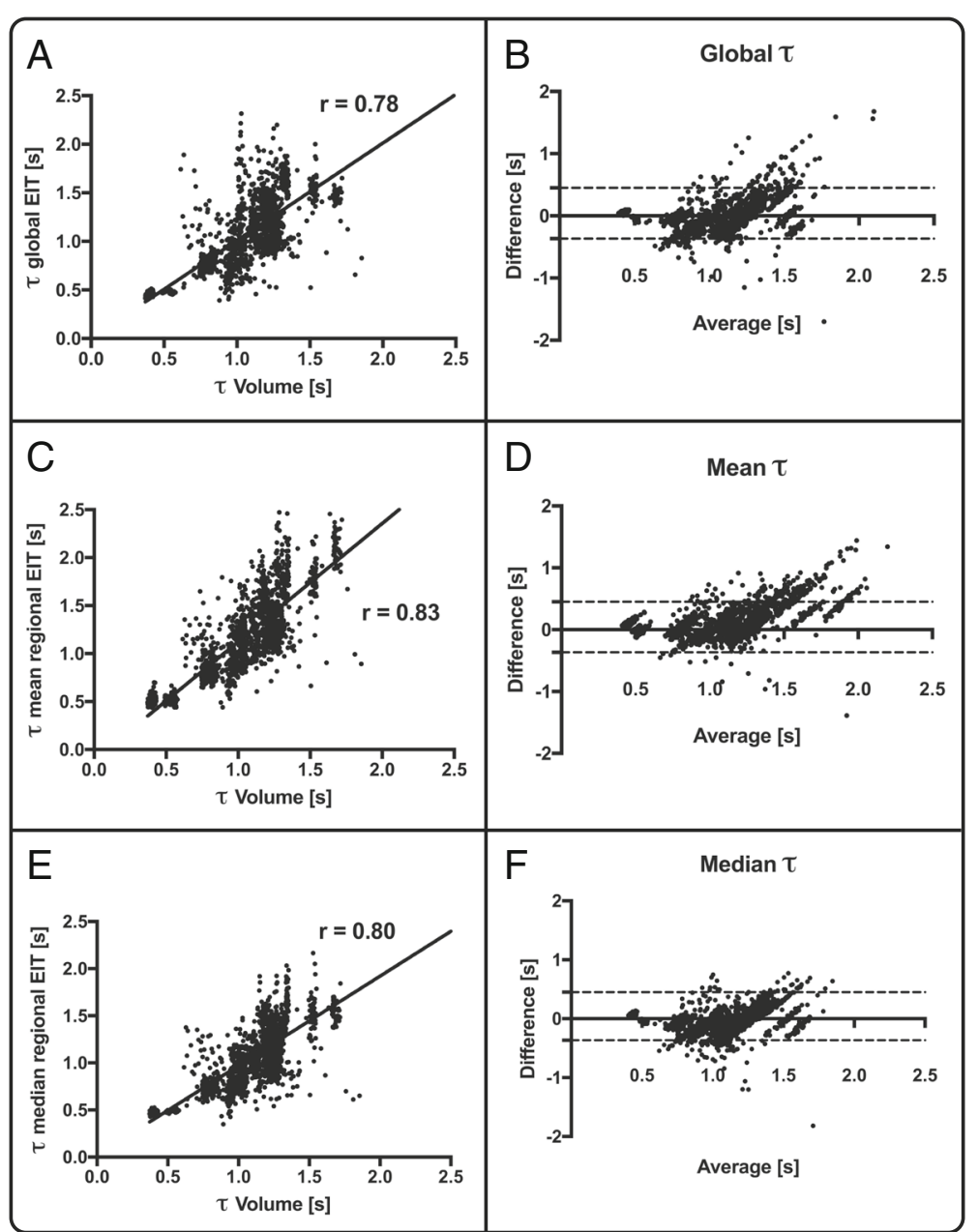

Fig. 3 Spearman correlation $r$ between global tau calculation and volume signal (a), mean regional electrical impedance tomography (EIT)derived tau (c) and median regional EIT-derived tau (e). The corresponding Bland-Altman analysis is displayed in $\mathbf{b}, \mathbf{d}$ and $\mathbf{f}$ 
pixel had no exponential fit, e.g. pixel from the heart or atelectasis without ventilation, this pixel was excluded from further analysis. Furthermore, the global impedance $(\Delta \mathrm{Z}(t) \mathrm{global})$ signal was calculated as the sum of all signals at any point of time. The start and end of expiration were determined, respectively from the global EIT signal. Then within this time sequence, for each single pixel the $75 \%$ amplitude was calculated as the start of the curve fitting (Fig. 2b) and a local minimum was used to define the end of expiration. However, the global signal is only used to define the time sequence of the expiration but start and end was defined pixelwise.

\section{Calculation of regional time constant $\tau_{\text {reg }}$}

Passive expiration resembles an exponential decay:

$$
V(t)=V_{0} \cdot e^{\frac{-t}{t}}+C
$$

where $\mathrm{V}(t)$ is the volume at that time point $t, \mathrm{~V}_{0}$ is the volume at the start of expiration, $t$ the time from the start at end-inspiration to the end of expiration, $\tau$ the expiratory time constant and $\mathrm{C}$ the end-expiratory volume (Fig. 1). The time constant $\tau$ represents the time for $\mathrm{V}(t)$ to exhale $2 / 3$ of its volume, with $3 \tau$ defining the time to reach at least $95 \%$ of complete exhalation. In mechanically ventilated patients, especially in COPD, exhalation may be incomplete during a tidal breath and, thus, in this case expiratory flow does not reach zero before the start of the next breath. The exhalation of each lung region correlates with an exponential decay in volume, which can be calculated. However, the expiratory volume curve is not typically exponential in mechanically ventilated patients [39] since the onset of expiration is mostly dominated by inertial effects and differs from the following parts of the exhalation curve. To overcome this problem, Lourens et al. [28] advised starting the analysis at $75 \%$ of the breath-wise maximum and therefore skip the first part of the exhalation curve for calculation. Furthermore, they demonstrated that expiratory time constants determined from the expiratory flowvolume curve using $75 \%$ of tidal volume were in closest agreement with the time constant obtained with interrupter measurements. Subsequently, the first $25 \%$ of the local signal amplitude was omitted; thus, $\tau$ was calculated from the remaining $75 \%$ of the pneumatic signal by fitting an exponential curve to the pneumatic signal and the global EIT signal, and to the signal of each pixel within the lung regions (Fig. 2). EIT signals stemming from lung areas with low or no ventilation, or non-exponential signals were excluded from $\tau$ calculations.

The expiratory time constants were assessed at airway opening in the whole respiratory system by curve fitting of the volume curve and compared with the time constants calculated from impedance changes over time measured by EIT (Figs. 1 and 2). Validation was performed by comparing the global expiratory time constant gained from the volume signal with the global signal from EIT, since no regional pneumatic information can be determined on a comparable pixel level. Figure 3 demonstrates the correlation between the pneumatic signal and all EITderived signals for every single breath recorded during the timeframe and for all PEEP levels. To estimate the robustness of our method, we calculated the regional coefficient of variation $(\mathrm{CV})$ for all breaths as standard deviation divided by the mean (Additional file 2: Figure S1).

\section{Statistics}

Correlation was tested between the time constants derived from the pneumatic volume curve and EIT-derived time constants by calculating Spearman's correlation coefficient. Every single breath was compared using both methods. Bland-Altman analysis was performed on the same data using GraphPad Prism version 7 (GraphPad Software, La Jolla, CA, USA).

Table 1 baseline characteristics of the patients

\begin{tabular}{|c|c|}
\hline Age (years) & $57 \pm 15$ \\
\hline Gender (female/male) & $4 / 10$ \\
\hline Pneumonia & $13 / 14$ \\
\hline History of COPD (GOLD II-IV) ${ }^{a}$ & $7 / 14$ \\
\hline $\mathrm{ARDS}^{\mathrm{a}}$ & $8 / 14$ \\
\hline SAPS $\|$ at admission & $35 \pm 10$ \\
\hline LTOT before & $4 / 14$ \\
\hline Home NIV before & $2 / 14$ \\
\hline Active smoking & $11 / 14$ \\
\hline Mortality & $3 / 14$ \\
\hline Days on mechanical ventilation & $36 \pm 26$ \\
\hline Days in ICU & $41 \pm 37$ \\
\hline \multicolumn{2}{|c|}{ Respiratory system mechanics and blood gas analysis } \\
\hline pH day 1 & $7.24 \pm 0.1$ \\
\hline $\mathrm{PaCO}_{2}$ day $1(\mathrm{mmHg})$ & $72 \pm 20$ \\
\hline $\mathrm{PaO}_{2}$ day $1(\mathrm{mmHg})$ & $82 \pm 19$ \\
\hline $\mathrm{P} / \mathrm{F}$ ratio day 1 (mmHg) & $124 \pm 41$ \\
\hline PEEP day $1\left(\mathrm{cmH}_{2} \mathrm{O}\right)$ & $14 \pm 2$ \\
\hline$P_{\text {insp }}$ day $1\left(\mathrm{cmH}_{2} \mathrm{O}\right)$ & $30 \pm 4$ \\
\hline Tidal volume day 1 (ml) & $470 \pm 88$ \\
\hline PEEP day $7\left(\mathrm{cmH}_{2} \mathrm{O}\right)$ & $13 \pm 2$ \\
\hline$P_{\text {insp }}$ day $7\left(\mathrm{cmH}_{2} \mathrm{O}\right)$ & $26 \pm 4$ \\
\hline Tidal volume day 7 (ml) & $450 \pm 101$ \\
\hline
\end{tabular}

Baseline characteristics of all patients included in the study COPD chronic obstructive pulmonary disease, GOLD Global Initiative for Chronic Obstructive Lung Disease, LTOT long-term oxygen therapy, SAPS Simplified Acute Physiology Score, NIV non-invasive ventilation, $\mathrm{PaCO}_{2}$ partial arterial pressure of carbon dioxide, $\mathrm{PaO}_{2}$ partial arterial pressure of oxygen, PEEP positive end-expiratory pressure, $P_{\text {insp }}$ peak inspiratory pressure ${ }^{a}$ May occur at the same time 


\section{Results}

Fourteen patients with severe respiratory failure with a mean SAPS II score of $35 \pm 10$ and a mean time on invasive mechanical ventilation of $36 \pm 26$ days were included in the study. All but one patient suffered from pneumonia as the leading cause of respiratory failure from different underlying diseases (Table 1).

The EIT-derived expiratory time constant was calculated in different lung diseases and conditions of invasive mechanical ventilation (Figs. 4, 5 and 6). Exemplarily, Fig. 4 shows three main diseases, i.e. a stiff lung, ARDS and COPD, demonstrating a huge variation in expiratory time constants and spatial distribution. Comparison of calculation methods (time constants derived from global EIT signal vs. mean or median of regional expiratory time constants) revealed strong correlation (Fig. 3) in all cases with correlation coefficients ranging from 0.72 (PEEP10/11) to 0.81 (PEEP 14/15; Fig. 3 and Additional file 3: Table S1). The overall correlation for the entire PEEP range was $0.83(p<0.001)$. The lowest bias and limits of agreement according to the Bland-Altman analysis were for the global EIT signal and the median of the regional expiratory time constants. In detail, overall the correlation was 0.78 with a bias of $0.02 \mathrm{~s}$ within the limits of agreement ranging from -0.50 to $0.53 \mathrm{~s}$ for $\tau$ calculated from the global impedance signal. Correlation for the $\tau$ calculated as the mean of all pixelwise regional impedance changes was 0.83 with a higher bias of $0.14 \mathrm{~s}$ within the limits ranging from -0.37 to $0.65 \mathrm{~s}$. Furthermore, correlation for the median $\tau$ derived from the same regional impedance changes was 0.80 (bias -0.03 , limits of agreement -0.50 to $0.22 \mathrm{~s}$ ).

Typical patient examples are given in Figs. 4 and 5, showing expiratory time constants lasting longer than $2 \mathrm{~s}$ in patients with severe COPD (Fig. 4c) and very short ones in restrictive lung diseases such as in restrictive allograft syndrome with pneumonia (Fig. 4a). Histograms revealed a narrow homogeneous frequency distribution of $\tau$ values in patients with restrictive lung diseases such as restrictive allograft syndrome or ARDS and a widespread inhomogeneous distribution with $\tau$ values ranging from 2 to $5 \mathrm{~s}$ in patients with COPD (Fig. 4c).

\section{Discussion}

This is the first study to demonstrate that breath-by-breath measurements of regional expiratory time constants by EIT
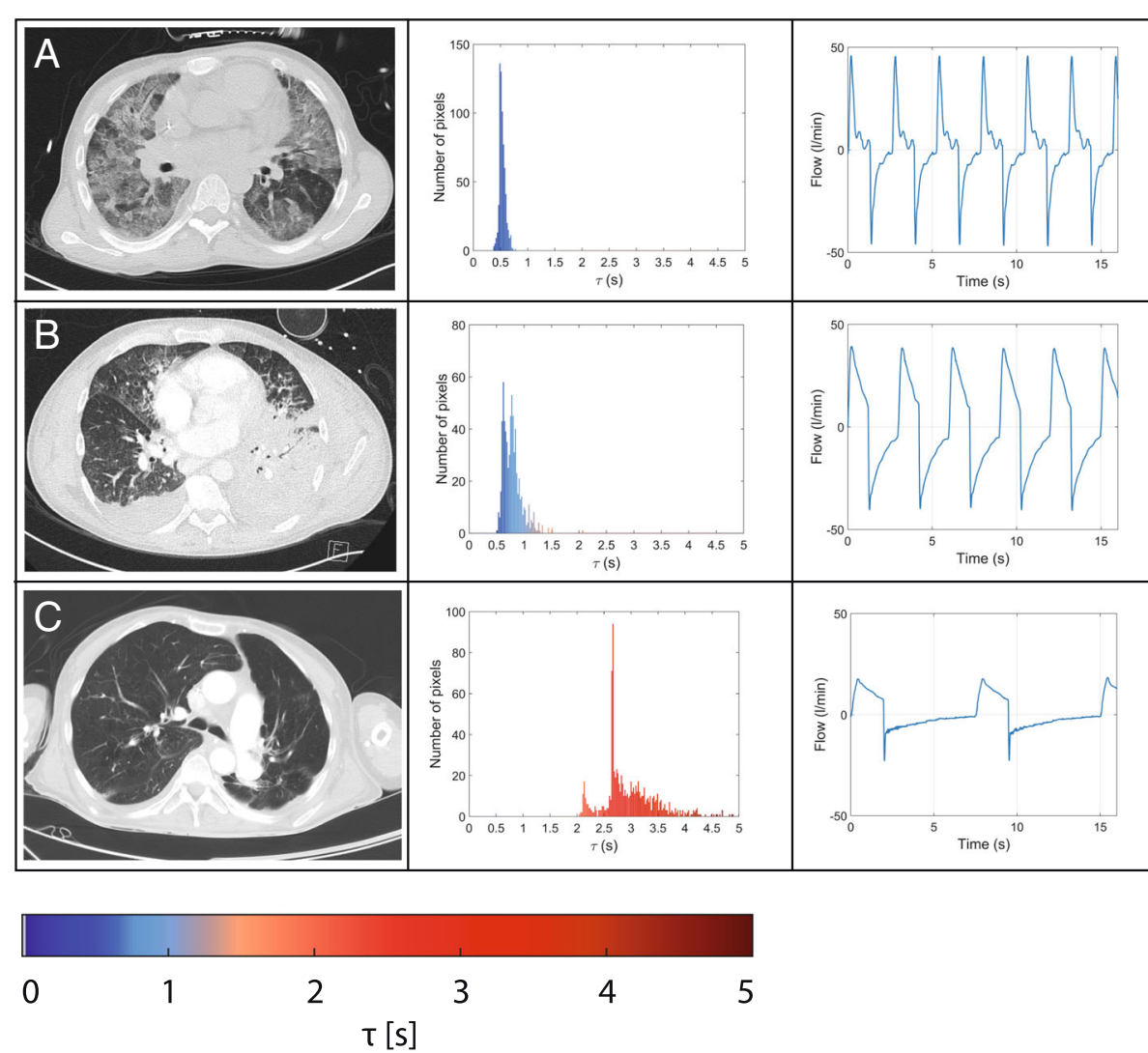

Fig. 4 Typical examples of frequency distribution of regional $\tau$ values calculated in a stiff lung (a), in acute respiratory distress syndrome with pneumonia (b) and in chronic obstructive pulmonary disease (c). From left to right: computed tomography scan, histogram of $\tau$ regional values and flow curve 


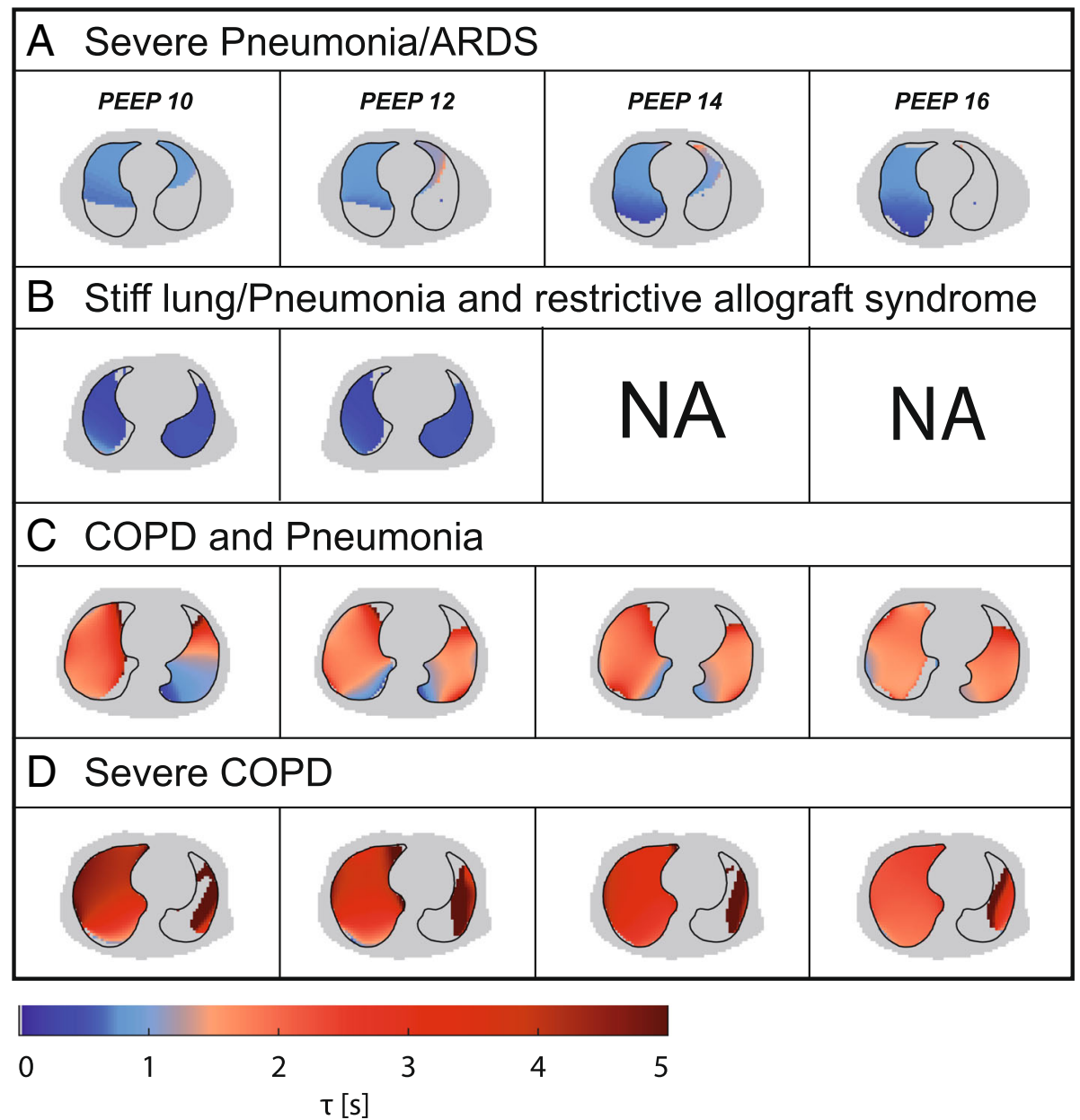

Fig. 5 Typical examples of $\mathrm{t}$ determined at different positive end-expiratory pressure (PEEP) levels in pneumonia/acute respiratory distress syndrome (ARDS) (a), in stiff lungs (b) and in chronic obstructive pulmonary disease (COPD) (c and $\mathbf{d}$ ) with its regional distribution. NA = not applicable

are technically feasible, reliable and valid in invasively ventilated patients with severe respiratory failure. In particular, EIT as used in the current study has provided new insights into the spatial and temporal distribution of airflow limitation also exemplarily shown in response to different PEEP settings in ARDS and COPD (Figs. 5 and 6). Thereby, the assessment of regional expiratory time constants clearly added previously unavailable information to the results achieved by the standard analysis derived from global flow and volume curves.

The algorithm to calculate the EIT-derived expiratory time constant was validated in patients with severe respiratory failure and was highly correlated (correlation coefficient approximately 0.80 ) with the pneumatic volume signal, demonstrating the usability of the EIT-derived expiratory time constants. EIT measurements were reproducible and robust (Additional file 2: Figure S1) under changing ventilation strategies, demonstrating the clinical usability of the system. Nevertheless, limits of agreement alternate depending on the type of disease, airflow obstruction, resulting time constant and at certain PEEP levels (Additional file 3: Table S1), in part reaching $0.5 \mathrm{~s}$. However, in the author's opinion, first the trend over time is more important than absolute numbers in daily clinical practice; second, in a real-time breath-by-breath analysis, single outliers as shown in the Bland-Altmann analysis, have a minor impact, especially for long time constants, since most of the values are in an accurate range. This reflects the advantage of EIT-based real-time measurements at the bedside with every breath. Third, the accuracy of the measurement can be further improved simply by averaging $5-10$ breaths over time without losing the regional information.

Our study shows the physiological influence of different PEEP levels on regional airflow limitations. These data are in line with current animal experiments, demonstrating that whole lung measures of strain do not accurately represent regional pulmonary mechanics [40]. Furthermore, Pulletz et al. demonstrated different time constants 


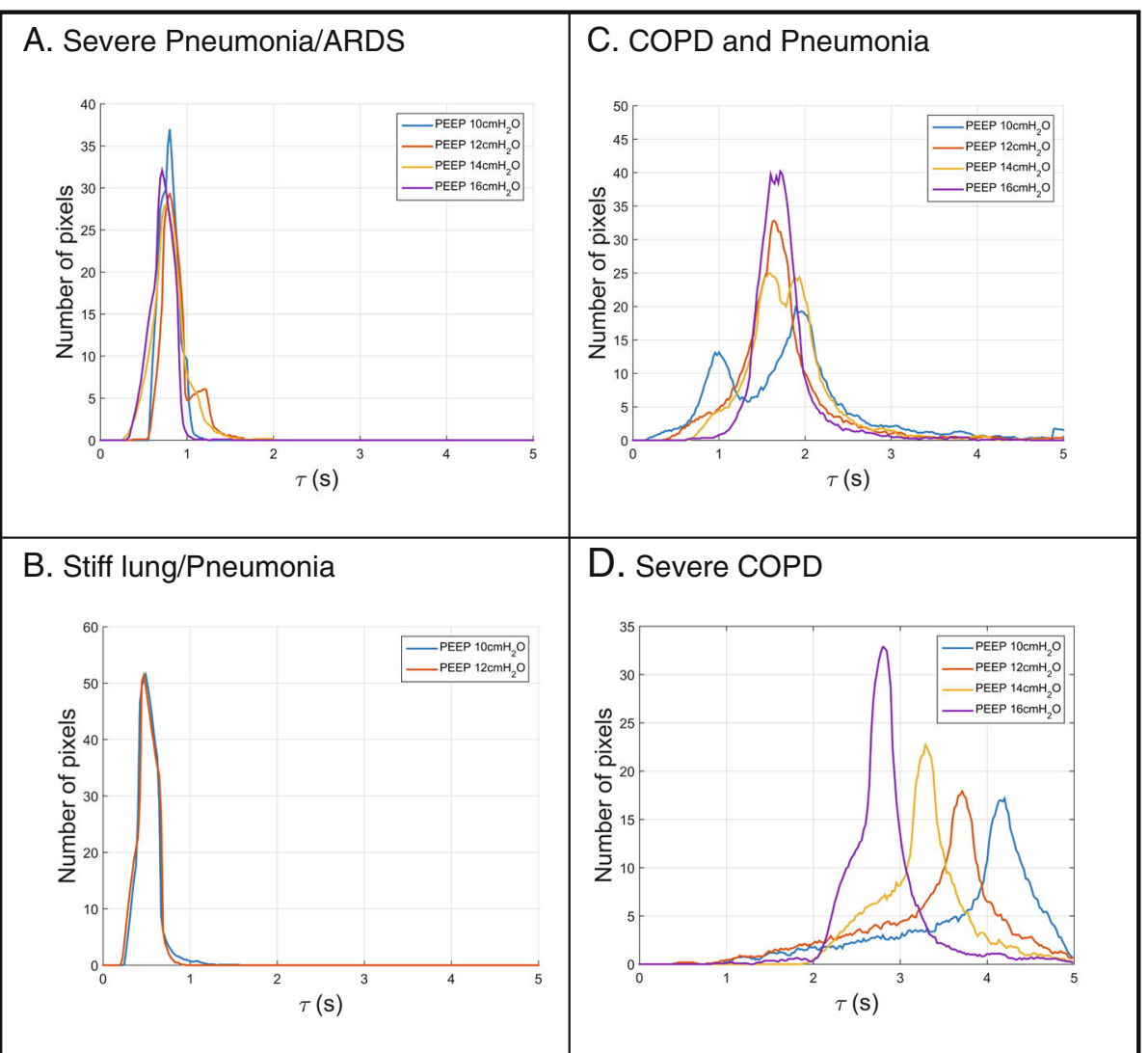

Fig. 6 Typical examples of $\tau$ determined at different positive end-expiratory pressure (PEEP) levels in pneumonia/acute respiratory distress syndrome (ARDS) (a), in stiff lungs (b) and in chronic obstructive pulmonary disease (COPD) (c and $\mathbf{d}$ ) displayed as pixel-wise histograms

measured by EIT in patients with ARDS, comparable to the example given in Fig. 4 [41], which in principle also holds true for preterm infants [42]. Thereby, beneficial and potentially harmful effects of PEEP were demonstrated in both ARDS and COPD alike. The illustrated example curves even demonstrate contradictory effects within a single patient, highlighting the importance of regional analysis. Furthermore, EIT effectively demonstrated the inhomogeneous emptying characteristics of different lung regions in severe COPD compared to more homogenous lungs in some patients with ARDS. Therefore, EIT-based expiratory time constant analysis could serve as a clinically useful bedside adjunct for defining the optimal PEEP level and ventilation strategy in different lung conditions. Furthermore, the breath-wise analysis opens the opportunity to determine regional trends over time to estimate the best overall ventilator settings.

Concerning the absolute values, the described method estimates the potential time the lung would need to fully deflate. Therefore, the time constant appears to be longer than clinically predicted but reflects the behavior of small airways and the difficulty of their respective dependent lung units to become fully deflated. One might speculate that the trending of $\tau$ over time might be as valuable as the absolute $\tau$ values per se. Furthermore, all patient examples given in the manuscript reflect images of regional lung function, which were matched with the morphological alterations in CT scan and global flow analysis, thereby, underlining the reliability of the method for use in clinical practice.

The study has, however, some limitations. First, the chosen algorithm to calculate the expiratory time constant is based on the hypothetical assumption of a complete expiration, which may not be achieved clinically at least in some patients with severe airflow obstruction. Therefore, in this scenario expiratory time constants as calculated by EIT might be higher than the actual time a lung region needs for expiration, an effect that becomes more pronounced with longer time constants and higher breathing frequencies. Second, for validation purposes the current study evaluates the expiratory time constant in deeply sedated patients without any breathing efforts, but not in spontaneously breathing patients. However, even in spontaneously breathing patients with high breathing frequency, EIT may gather results comparable to standard lung function testing where breathing commands are given. Third, in general, EIT with the current technology does not cover the time constants from all regions of the lung. 
However, in the current study at least $10 \mathrm{~cm}$ from up to down are covered with the EIT belt [9]. Finally, repetitive measurements in the same patient to obtain even more robust data were not ethically possible due to the severity of the disease.

\section{Conclusions}

In conclusion, EIT-based breath-by-breath determination of regional expiratory time constant is technically feasible, reliable and valid in invasively ventilated patients with severe respiratory failure. In addition, different PEEP levels were exemplarily shown to have an influence on the distribution pattern of regional time constants in different types of acute severe lung failure. Future studies should determine the clinical impact of measuring airflow obstruction on a regional basis in patients with acute or chronic respiratory failure requiring mechanical ventilation.

\section{Additional files}

Additional file 1: Figure S2. Image reconstruction and segmentation of corresponding CT scan. (PDF $6665 \mathrm{~kb}$ )

Additional file 2: Figure S1. Coefficient of variation in EIT-derived $\tau$ calculations in 14 patients. (PDF $1276 \mathrm{~kb}$ )

Additional file 3: Table S1. Correlation, bias and limits of agreement for different PEEP levels. (DOCX 14 kb)

\section{Abbreviations}

ARDS: Acute respiratory distress syndrome; COPD: Chronic obstructive pulmonary disease; CT: Computed tomography; EIT: Electrical impedance tomography; PEEP: Positive end-expiratory pressure; RASS: Richmond Agitation Sedation Scale; SAPS: Simplified Acute Physiology Score

\section{Funding}

Swisstom AG, Switzerland provided electrode belts free of charge. The authors state that neither the study design, results and interpretation of the findings nor any other subject discussed in the submitted manuscript was dependent on this support.

\section{Availability of data and materials}

All data generated or analyzed during this study are included in this published article.

\section{Authors' contributions}

CK and AW had access to all data and take responsibility for the integrity of the data and the accuracy of the data analysis. CK, WW, AW and SHB designed the study. PR, TS and SS participated in data acquisition and analysis. CK, AW, WW and SHB designed the concept of the manuscript; all the other authors contributed to the final drafting of the manuscript. All authors read and approved the final manuscript.

\section{Ethics approval and consent to participate}

The present study was approved by the Institutional Review Board (Ethical committee of the University Witten/Herdecke) and registered at the German Clinical Trial Register and the WHO trial register (DRKS00011650/ U1111-1192-0396).

\section{Consent for publication}

The manuscript has been read and its submission approved by all co-authors. Patients were prospectively included after informed consent was obtained from the legal caregiver.

\section{Competing interests}

CK and SS received travel grants and lecture fees from Maquet Cardiopulmonary, Rastatt, Germany. WW received fees for advisory board meetings and lectures from Maquet Cardiopulmonary, Rastatt, Germany. Andreas Waldmann is an employee of Swisstom AG. PR and TS have no competing interests. SHB was co-founder and chief medical director of Swisstom until October 2016.

\section{Publisher's Note}

Springer Nature remains neutral with regard to jurisdictional claims in published maps and institutional affiliations.

\section{Author details}

${ }^{1}$ Department of Pneumology and Critical Care Medicine, Cologne-Merheim Hospital, Kliniken der Stadt Köln gGmbH, Witten/Herdecke University Hospital, Ostmerheimer Strasse 200, D-51109 Cologne, Germany. ${ }^{2}$ Swisstom AG, Schulstrasse 1, 7302 Landquart, Switzerland. ${ }^{3}$ Budapest University of Technology and Economics, Budapest, Hungary. ${ }^{4}$ Klinik und Poliklinik für Anästhesiologie und Intensivtherapie, Universitätsmedizin Rostock, Schillingallee 35, D-18057 Rostock, Germany.

Received: 20 February 2018 Accepted: 27 July 2018

Published online: 21 September 2018

References

1. Force ADT, Ranieri VM, Rubenfeld GD, Thompson BT, Ferguson ND, Caldwell E, Fan E, Camporota L, Slutsky AS. Acute respiratory distress syndrome: the Berlin definition. JAMA. 2012:307(23):2526-33.

2. Chandra D, Stamm JA, Taylor B, Ramos RM, Satterwhite L, Krishnan JA, Mannino D, Sciurba FC, Holguin F. Outcomes of noninvasive ventilation for acute exacerbations of chronic obstructive pulmonary disease in the United States, 1998-2008. Am J Respir Crit Care Med. 2012;185(2):152-9.

3. Seymour CW, Gomez H, Chang CH, Clermont G, Kellum JA, Kennedy J, Yende S, Angus DC. Precision medicine for all? Challenges and opportunities for a precision medicine approach to critical illness. Crit Care. 2017;21(1):257.

4. Dhand R. Ventilator graphics and respiratory mechanics in the patient with obstructive lung disease. Respir Care. 2005;50(2):246-61. discussion 259-261

5. Brochard L, Martin GS, Blanch L, Pelosi P, Belda FJ, Jubran A, Gattinoni L, Mancebo J, Ranieri VM, Richard JC, et al. Clinical review: respiratory monitoring in the ICU - a consensus of 16. Crit Care. 2012:16(2):219.

6. Yoshida T, Torsani V, Gomes S, De Santis RR, Beraldo MA, Costa EL, Tucci MR, Zin WA, Kavanagh BP, Amato MB. Spontaneous effort causes occult pendelluft during mechanical ventilation. Am J Respir Crit Care Med. 2013; 188(12):1420-7.

7. Yoshida T, Roldan R, Beraldo MA, Torsani V, Gomes S, De Santis RR, Costa EL, Tucci MR, Lima RG, Kavanagh BP, et al. Spontaneous effort during mechanical ventilation: maximal injury with less positive end-expiratory pressure. Crit Care Med. 2016:44(8):e678-88.

8. Talmor D, Sarge T, Malhotra A, O'Donnell CR, Ritz R, Lisbon A, Novack V, Loring SH. Mechanical ventilation guided by esophageal pressure in acute lung injury. N Engl J Med. 2008;359(20):2095-104.

9. Frerichs I, Amato MB, van Kaam AH, Tingay DG, Zhao Z, Grychtol B, Bodenstein M, Gagnon H, Bohm SH, Teschner E, et al. Chest electrical impedance tomography examination, data analysis, terminology, clinical use and recommendations: consensus statement of the TRanslational EIT developmeNt stuDy group. Thorax. 2017;72(1):83-93.

10. Costa EL, Lima RG, Amato MB. Electrical impedance tomography. Curr Opin Crit Care. 2009;15(1):18-24.

11. Morais CCA, Koyama Y, Yoshida T, Plens GM, Gomes S, Lima C, Ramos OP, Pereira SM, Kawaguchi N, Yamamoto H, et al. High positive end-expiratory pressure renders spontaneous effort non-injurious. Am J Respir Crit Care Med. 2018;197(10):1285-96.

12. Grieco DL, Mura B, Bisanti A, Tagliaferri C, Maviglia R, Antonelli M. Electrical impedance tomography to monitor lung sampling during broncho-alveolar lavage. Intensive Care Med. 2016;42(6):1088-9.

13. Bodenstein M, David M, Markstaller K. Principles of electrical impedance tomography and its clinical application. Crit Care Med. 2009;37(2):713-24.

14. Frerichs I, Becher T, Weiler N. Electrical impedance tomography imaging of the cardiopulmonary system. Curr Opin Crit Care. 2014;20(3):323-32. 
15. Moerer O, Hahn G, Quintel M. Lung impedance measurements to monitor alveolar ventilation. Curr Opin Crit Care. 2011;17(3):260-7.

16. Eronia N, Mauri T, Maffezzini E, Gatti S, Bronco A, Alban L, Binda F, Sasso T, Marenghi C, Grasselli G, et al. Bedside selection of positive end-expiratory pressure by electrical impedance tomography in hypoxemic patients: a feasibility study. Ann Intensive Care. 2017;7(1):76.

17. Franchineau G, Brechot N, Lebreton G, Hekimian G, Nieszkowska A, Trouillet $J$, Leprince P, Chastre J, Luyt CE, Combes A, et al. Bedside contribution of electrical impedance tomography to setting positive end-expiratory pressure for extracorporeal membrane oxygenation-treated patients with severe acute respiratory distress syndrome. Am J Respir Crit Care Med. 2017; 196(4):447-57.

18. Blankman P, Hasan D, Erik G, Gommers D. Detection of 'best' positive end-expiratory pressure derived from electrical impedance tomography parameters during a decremental positive end-expiratory pressure trial. Crit Care. 2014;18(3):R95.

19. Blankman P, Hasan D, van Mourik MS, Gommers D. Ventilation distribution measured with EIT at varying levels of pressure support and neurally adjusted ventilatory assist in patients with ALI. Intensive Care Med. 2013;39(6):1057-62

20. Mauri T, Bellani G, Confalonieri A, Tagliabue P, Turella M, Coppadoro A, Citerio G, Patroniti N, Pesenti A. Topographic distribution of tidal ventilation in acute respiratory distress syndrome: effects of positive end-expiratory pressure and pressure support. Crit Care Med. 2013;41(7):1664-73.

21. Spadaro S, Mauri T, Bohm SH, Scaramuzzo G, Turrini C, Waldmann AD, Ragazzi R, Pesenti A, Volta CA. Variation of poorly ventilated lung units (silent spaces) measured by electrical impedance tomography to dynamically assess recruitment. Crit Care. 2018;22(1):26.

22. Costa EL, Borges JB, Melo A, Suarez-Sipmann F, Toufen C Jr, Bohm SH, Amato MB. Bedside estimation of recruitable alveolar collapse and hyperdistension by electrical impedance tomography. Intensive Care Med. 2009;35(6):1132-7.

23. Meier T, Luepschen $H$, Karsten J, Leibecke T, Grossherr M, Gehring H Leonhardt S. Assessment of regional lung recruitment and derecruitment during a PEEP trial based on electrical impedance tomography. Intensive Care Med. 2008;34(3):543-50.

24. Pulletz S, Adler A, Kott M, Elke G, Gawelczyk B, Schadler D, Zick G, Weiler N, Frerichs I. Regional lung opening and closing pressures in patients with acute lung injury. J Crit Care. 2012;27(3):323 e311-28.

25. Zick G, Elke G, Becher T, Schadler D, Pulletz S, Freitag-Wolf S, Weiler N, Frerichs I. Effect of PEEP and tidal volume on ventilation distribution and end-expiratory lung volume: a prospective experimental animal and pilot clinical study. PLoS One. 2013;8(8):e72675.

26. Wrigge $H$, Zinserling J, Muders T, Varelmann D, Gunther U, von der Groeben C, Magnusson A, Hedenstierna G, Putensen C. Electrical impedance tomography compared with thoracic computed tomography during a slow inflation maneuver in experimental models of lung injury. Crit Care Med. 2008;36(3):903-9.

27. Victorino JA, Borges JB, Okamoto VN, Matos GF, Tucci MR, Caramez MP, Tanaka H, Sipmann FS, Santos DC, Barbas CS, et al. Imbalances in regional lung ventilation: a validation study on electrical impedance tomography. Am J Respir Crit Care Med. 2004:169(7):791-800.

28. Lourens MS, van den Berg B, Aerts JG, Verbraak AF, Hoogsteden HC, Bogaard JM. Expiratory time constants in mechanically ventilated patients with and without COPD. Intensive Care Med. 2000;26(11):1612-8.

29. Lourens MS, Ali L, van den Berg B, Verbraak AF, Bogaard JM, Hoogsteden HC, Babuska R. Estimation of expiratory time constants via fuzzy clustering. J Clin Monit Comput. 2002:17(1):15-22.

30. Marini JJ, Crooke PS 3rd, Truwit JD. Determinants and limits of pressurepreset ventilation: a mathematical model of pressure control. J Appl Physiol (1985). 1989;67(3):1081-92.

31. Brunner JX, Laubscher TP, Banner MJ, lotti G, Braschi A. Simple method to measure total expiratory time constant based on the passive expiratory flow-volume curve. Crit Care Med. 1995;23(6):1117-22.

32. Henderson WR, Dominelli PB, Molgat-Seon Y, Lipson R, Griesdale DE, Sekhon M, Ayas N, Sheel AW. Effect of tidal volume and positive endexpiratory pressure on expiratory time constants in experimental lung injury. Physiol Rep. 2016;4(5) https://doi.org/10.14814/phy2.12737.

33. Vogt B, Pulletz S, Elke G, Zhao Z, Zabel P, Weiler N, Frerichs I. Spatial and temporal heterogeneity of regional lung ventilation determined by electrical impedance tomography during pulmonary function testing J Appl Physiol (1985). 2012;113(7):1154-61.
34. Vogt B, Zhao Z, Zabel P, Weiler N, Frerichs I. Regional lung response to bronchodilator reversibility testing determined by electrical impedance tomography in chronic obstructive pulmonary disease. Am J Physiol Lung Cell Mol Physiol. 2016:311(1):L8-L19.

35. Kostakou E, Barrett N, Camporota L. Electrical impedance tomography to determine optimal positive end-expiratory pressure in severe chronic obstructive pulmonary disease. Crit Care. 2016;20(1):295.

36. Frerichs I, Achtzehn U, Pechmann A, Pulletz S, Schmidt EW, Quintel M, Weiler N. High-frequency oscillatory ventilation in patients with acute exacerbation of chronic obstructive pulmonary disease. J Crit Care. 2012; 27(2):172-81.

37. Waldmann AD, Wodack KH, März A, Ukere A, Trepte CJ, Böhm SH, Reuter DA. Performance of novel patient Interface for electrical impedance tomography applications. J Med Biol Eng. 2017;37(4):561-6.

38. Ukere A, Marz A, Wodack KH, Trepte CJ, Haese A, Waldmann AD, Bohm SH, Reuter DA. Perioperative assessment of regional ventilation during changing body positions and ventilation conditions by electrical impedance tomography. Br J Anaesth. 2016;117(2):228-35.

39. Guttmann J, Eberhard L, Fabry B, Bertschmann W, Zeravik J, Adolph M, Eckart J, Wolff G. Time constant/volume relationship of passive expiration in mechanically ventilated ARDS patients. Eur Respir J. 1995;8(1):114-20.

40. Henderson WR, Molgat-Seon Y, Vos W, Lipson R, Ferreira F, Kirby M, Holsbeke CV, Dominelli PB, Griesdale DE, Sekhon M, et al. Functional respiratory imaging, regional strain, and expiratory time constants at three levels of positive end expiratory pressure in an ex vivo pig model. Physiol Rep. 2016:4(23):e13059.

41. Pulletz S, Kott M, Elke G, Schadler D, Vogt B, Weiler N, Frerichs I. Dynamics of regional lung aeration determined by electrical impedance tomography in patients with acute respiratory distress syndrome. Multidiscip Respir Med. 2012;7(1):44.

42. Miedema $M$, de Jongh $F H$, Frerichs I, van Veenendaal MB, van Kaam AH Regional respiratory time constants during lung recruitment in highfrequency oscillatory ventilated preterm infants. Intensive Care Med. 2012; 38(2):294-9

\section{Ready to submit your research? Choose BMC and benefit from:}

- fast, convenient online submission

- thorough peer review by experienced researchers in your field

- rapid publication on acceptance

- support for research data, including large and complex data types

- gold Open Access which fosters wider collaboration and increased citations

- maximum visibility for your research: over $100 \mathrm{M}$ website views per year

At $\mathrm{BMC}$, research is always in progress.

Learn more biomedcentral.com/submissions 